\title{
Evaluation of quantitative polymerase chain reaction to assess nos $Z$ gene prevalence in mixed microbial communities
}

\author{
Steven D. Siciliano, Wai Ma, and Shane Powell
}

\begin{abstract}
The usefulness of quantitative polymerase chain reaction (QPCR) to measure nosZ gene prevalence in a multitemplate reaction was assessed by comparing 19 nos $Z$ template DNA samples and 91 model communities. Efficiencies of the QPCR varied but were not significantly different among nos $Z$ genotypes and were not linked to genetic distance from Ralstonia eutropha. nosZ genotype QPCR efficiencies obtained from isolated denitrifiers were higher (84.8\%) than those obtained from excised denaturing gradient gel electrophoresis bands or clones of PCR products from total community DNA (ca. 60\%). Analysis of the model communities indicated that QPCR accurately predicts gene prevalence in communities composed of up to six templates.
\end{abstract}

Key words: denitrification, nosZ, quantitative PCR, microbial ecology, Antarctic, Arctic, soils.

Résumé : L'utilité de la réaction par polymérase en chaîne quantitative (QPCR) pour mesurer la prévalence du gène nosZ lors d'une réaction sur matrices multiples a été évaluée en comparant 19 matrices d'ADN et 91 communautés modèles. L'efficacité de la QPCR variait mais il n'y avait pas de différences significatives en fonction des génotypes de nos $Z$ et elles n'étaient pas reliées à la distance génétique de Ralstonia eutropha. L'efficacité de la QPCR dans la détection de génotypes de nosZ obtenus d'organismes de dénitrification isolés était plus élevée $(84,8 \%)$ que celle obtenue à partir d'échantillons excisés de bandes d'électrophorèse sur gels en gradient ou de clones de produits PCR amplifiés à partir de l'ADN de la communauté totale (ca. $60 \%$ ). L'analyse de communautés modèles a indiqué que la QPCR prédit adéquatement la prévalence d'un gène dans une communauté comprenant jusqu'à six matrices.

Mots-clés : dénitrification, nosZ, PCR quantitative, écologie microbienne, Antarctique, Arctique, sols.

[Traduit par la Rédaction]

\section{Introduction}

Microbial ecologists use an array of techniques to gather data on the prevalence, distribution, and richness of microbial communities. These techniques range from cultivation and enzymatic techniques to nucleic acid analyses. All of these techniques have advantages and limitations. Quantitative polymerase chain reaction (QPCR) is a recently developed nucleic acid technique that has rapidly gained popularity. With the QPCR technique, primers are used to amplify a specific amplicon that is typically short (i.e., less than $500 \mathrm{bp}$ ). Amplicon concentrations are assessed each QPCR cycle by the generation of fluorescence from either a double-stranded DNA fluorescent dye or a probe-quencher system. As shown in eq. 1 , the fractional number of cycles required to reach a detectable fluorescence is proportional to the initial number and size of target genes present in the sample (Rutledge and Cote 2003):

Received 22 August 2006. Revision received 21 December 2006. Accepted 9 January 2007. Published on the NRC Research Press Web site at cjm.nrc.ca on 22 June 2007.

S.D. Siciliano ${ }^{1}$ and W. Ma. Department of Soil Science, University of Saskatchewan, Saskatoon, SK S7N 5A8, Canada. S. Powell. School of Agricultural Science, University of Tasmania, Private Bag 54, Hobart TAS 7001, Australia.

${ }^{1}$ Corresponding author (e-mail: steven.siciliano@usask.ca).
[1] $\log \left(N_{0}\right)=-\log (E+1) \cdot C_{\mathrm{t}}+\log \left(N_{\mathrm{t}}\right)$

in which $N_{0}$ is the initial number of target genes, $E$ is the PCR efficiency, $C_{t}$ is the fractional number of PCR cycles required to reach the fluorescence threshold, and $N_{\mathrm{t}}$ is the number amplicons at the fluorescence threshold. The fluorescence threshold is a function of number of amplicons, amplicon size, and the sensitivity of the instrument. One can estimate the $N_{0}$ in a sample by plotting $\log \left(N_{0}\right)$ versus $C_{\mathrm{t}}$ for a standard and then solving for $N_{0}$ when $C_{\mathrm{t}}$ is observed for an unknown sample. See Rutledge and Cote (2003) for excellent discussions on the mathematics of QPCR and the associated quality assurance and quality control parameters for the PCR portion of QPCR.

QPCR was developed and validated for single template reactions. Recently, molecular ecologists have begun using QPCR to assess specific genes in complex communities such as bacterial populations (Ott et al. 2004; Fierer et al. 2005), ammonia oxidizers (Hall et al. 2002), catabolic genes (Beller et al. 2002; Baldwin et al. 2003), metal reduction genes (Sun et al. 2004), and antibiotic genes (Smith et al. 2004). This approach of assessing a single gene within different DNA templates, some of which contain base pair differences between the template and the primers, is termed a multi-template QPCR reaction. PCR efficiency may be influenced by differences in base pair matching between primers and templates or by differences in the secondary structure of the target gene's genomic region (Anderson et 
al. 2003). For example, investigators comparing the gene prevalence of the 23S rRNA gene with the hlyA gene within Listeria monocytogenes observed a 1.9:1 ratio despite a known 6:1 ratio from complete genome analysis (Nogva and Rudi 2004). The investigators speculated that this discrepancy may be caused by differences in the flanking sequences of the 23S rRNA gene sequence.

For QPCR to be valid, one must assume that the PCR efficiency, or $E$, is similar between the standard and the various templates in the environmental DNA sample and among the templates within the sample. Many factors influence PCR efficiency including but not limited to the following: presence of inhibitors, initial target concentrations, concentration of reaction components such as $\mathrm{MgCl}_{2}$, primer annealing, temperature-time profiles, and dye type (Suzuki and Giovannoni 1996; Polz and Cavanaugh 1998; Nogva and Rudi 2004). Several of these factors are sequence specific and, thus, inherent to multi-template QPCR reaction. The GC content of upstream and downstream sequences of the target gene greatly influences secondary structure stability, making certain structures more energetically stable and so less likely to amplify at a given temperature (Freeman et al. 1999; Nogva and Rudi 2004). The use of SYBR Green also has a sequence-specific effect on PCR efficiency, with SYBR altering PCR efficiencies of certain genes more than others (Giglio et al. 2003). Finally, all PCR reactions contain three types of sequences with differing PCR efficiencies: the original target template, "long products" that have a definite $5^{\prime}$ but an indefinite $3^{\prime}$ end, and "short products" that have defined $5^{\prime}$ and $3^{\prime}$ ends (Nogva and Rudi 2004). These templates also have differing amplification efficiencies, although the exact differences are still not clearly known.

Despite the importance of efficiency in a multi-template reaction, few studies have investigated PCR efficiencies. In one study, investigators developing a QPCR system for hydrocarbon degraders based on the gene $b s s A$, which encodes for the $\alpha$-subunit of benzylsuccinate synthase, found a $3.7 \%$ difference in the slope of $\log \left(N_{0}\right)$ versus $C_{\mathrm{t}}$ among three toluene-degrading strains (Beller et al. 2002). This equates to a difference in PCR efficiency of $\pm 11 \%$. In another study, investigators researched the development of a universal primer set for intestinal bacteria and evaluated the efficiency of detection across 10 bacterial species commonly found in that system (Ott et al. 2004). Using the data from that study, the PCR efficiency for the bacterial species can be calculated. The range $(47 \%-57 \%)$ is much lower than the $90 \%$ efficiency that one would expect for an optimized system (Rutledge and Cote 2003; Nogva and Rudi 2004).

The objective of our study was to evaluate the use of QPCR in a typical molecular ecology context. Ecologists often use a gene conserved across a range of bacterial genera to assess the prevalence of that gene in response to ecological stressors. One such gene used in our laboratory is the nos $Z$ gene, which encodes nitrous oxide reductase and is a diagnostic gene for denitrifying bacteria. Denitrifying bacteria can use nitrate as a terminal electron acceptor and are found in diverse environments. Our goal was to evaluate how PCR efficiencies varied among templates and to determine whether QPCR could accurately predict nos $Z$ abundance in multi-template reactions. For our purposes we define template as a single nos $Z$ sequence. Thus, in a total community DNA extract of a denitrifying community that contains more than one type of denitrifier, one would expect to find multiple templates for the QPCR reaction. We collected nos $Z$ templates from a wide variety of environments and techniques to represent a worst-case scenario for differences between PCR efficiencies of the same gene target.

\section{Materials and methods}

\section{Isolation of dentrifying bacteria from Antarctic soil}

Soil from the Old Casey Station, close by Australia's Casey Station in east Antarctica $\left(66^{\circ} 17^{\prime} \mathrm{S}, 110^{\circ} 32^{\prime} \mathrm{E}\right)$, is contaminated with a range of hydrocarbons, primarily from special-blend Antarctic diesel. The isolation of denitrifying bacteria from this soil and the sequencing of their nos $Z$ genes have been described in another study (Powell et al. 2006). In summary, hydrocarbon-contaminated soil from $30 \mathrm{~cm}$ depth was diluted in sterile phosphate-buffered saline and spread plated onto YTSN plates (per litre: $0.25 \mathrm{~g}$ yeast extract, $0.25 \mathrm{~g}$ tryptone, $0.25 \mathrm{~g}$ starch, $0.5 \mathrm{~g} \mathrm{NaNO}_{3}$, and $15 \mathrm{~g}$ agar) (Siciliano et al. 2000). The plates were incubated at $10{ }^{\circ} \mathrm{C}$ in GasPaks ${ }^{\mathrm{TM}}$ (BBL, Franklin Lakes, New Jersey). After 3 weeks, colonies were picked from the plates and subcultured until pure. DNA was extracted from isolates that were able to consume $\mathrm{N}_{2} \mathrm{O}$ by boiling isolates in TBE buffer (0.09 mol/L Tris, $0.9 \mathrm{~mol} / \mathrm{L}$ boric acid, and $2 \mathrm{mmol} / \mathrm{L}$ EDTA). This was extracted with 25:24:1 phenol chloroform - isoamyl alcohol, and the DNA was precipitated with cold $95 \%$ ethanol and resuspended in $10 \mathrm{mmol} / \mathrm{L}$ Tris (pH 8.0). A fragment of the nos $Z$ gene was amplified with the primers nosZF (CGYTGTTCMTCGACAGCCAG) and nosZR (CATGTGCAGNGCRTGGCAGAA) (Kloos et al. 2001). Each $20 \mu \mathrm{L}$ PCR reaction contained $10 \mu \mathrm{L}$ of MasterMix $^{\text {TM }}$ (Qiagen, Hilden, Germany), 10 pmol of each primer, and $1 \mu \mathrm{L}$ of template DNA extracted from the isolates. The fragments were amplified in a RoboCycler ${ }^{\mathrm{TM}}$ (Stratagene, La Jolla, California) with the following thermal cycling conditions: $95{ }^{\circ} \mathrm{C}$ for $5 \mathrm{~min}$; followed by 30 cycles of $94{ }^{\circ} \mathrm{C}$ for $40 \mathrm{~s}, 53{ }^{\circ} \mathrm{C}$ for $40 \mathrm{~s}, 72{ }^{\circ} \mathrm{C}$ for $1 \mathrm{~min}$; followed by a final extension at $72{ }^{\circ} \mathrm{C}$ for $10 \mathrm{~min}$. The PCR products were cleaned up using the Qiaquick ${ }^{\mathrm{TM}}$ PCR clean-up kit (Qiagen) and were sequenced at the Plant Biotechnology Institute (National Research Council, Canada) on an ABI sequencer (Applied Biosystems, Foster City, California).

\section{Cloning of nosZ fragments from Arctic soil}

Truelove Lowland, $75^{\circ} 40^{\prime} \mathrm{N}, 84^{\circ} 35^{\prime} \mathrm{W}$, is one in a series of coastal lowlands on Devon Island, Nunavut, Canada, and has been the subject of a previous soil study (Lev and King 1999). It covers an area of $42 \mathrm{~km}^{2}$ and is bound to the west and north by Jones Sound ( $24 \mathrm{~km}$ of shoreline) and to the east and south by two escarpments rising close to $300 \mathrm{~m}$ above sea level. Soil samples were collected from the lower foot slope of the raised beach ridge between Fish Lake and "Pooh Pond." The soils of the lower foreslope are brunisolic eutric turbic cryosols and are covered by lichen (Alectoria sp.) and upland sedges (Eriophorum sp.). Soil DNA was extracted directly from approximately $0.7 \mathrm{~g}$ of bulk soil with the UltraClean ${ }^{T M}$ Soil DNA Isolation Kit (Mo Bio Laborato- 
Fig. 1. Unrooted phylogenetic tree showing relationship of nos $Z$ sequences obtained by cloning (indicated as clone), cultivation (indicated as isolate), or polymerase chain reaction - denaturing gradient gel electrophoresis (indicated as DGGEband). Bolded sequences are sequences used in constructing the model communities. Accession numbers of nos $Z$ genes are in square brackets.

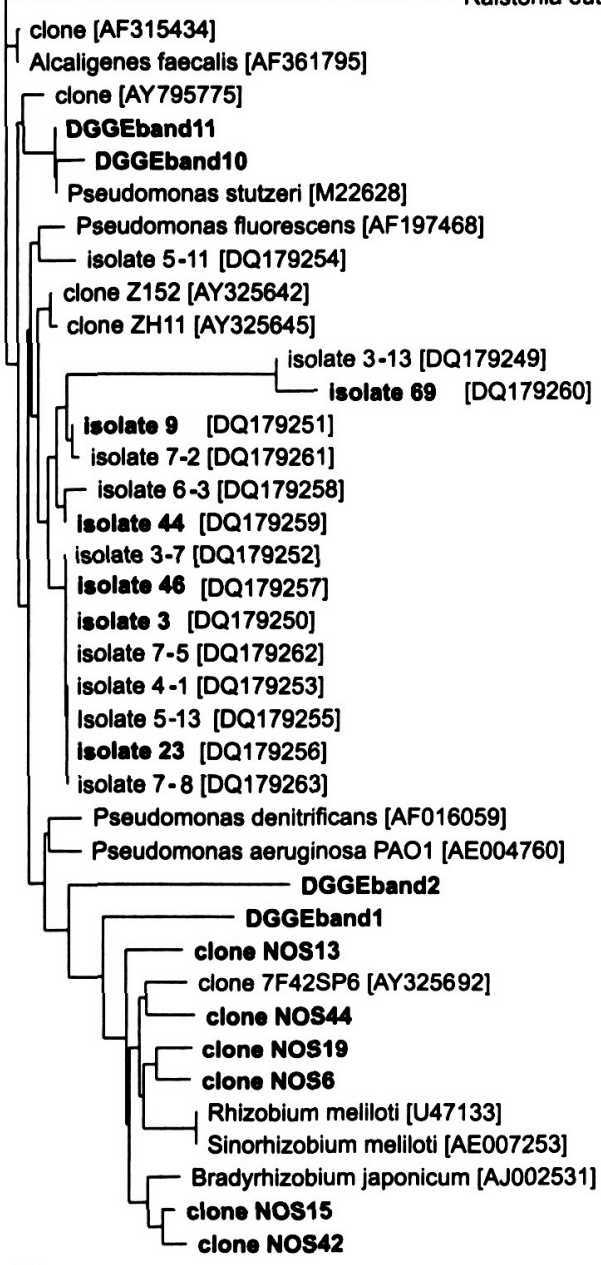

ries, Carlsbad, California.). DNA extracts were purified by polyvinylpolypyrrolidone columns (Berthelet et al. 1996). DNA yield was between 5.7 and $16 \mu \mathrm{g} / \mathrm{g}$ soil, as determined by spectrophotometry using an Ultrospec 2000 ultraviolet (UV)/visible spectrophotometer (Pharmacia Biotech, Cambridge, UK). Fragments of the nos $Z$ gene were amplified as described above. PCR products of nos $Z$ amplifications were separated by cloning. Five replicate amplification reactions (20 $\mu \mathrm{L}$ each) from the same sample extract were used to minimize stochastic biases present in PCR. The reactions were made with $4 \mu \mathrm{L}$ of template DNA using the Taq PCR Master Mix ${ }^{\mathrm{TM}}$ and the nosZF and nosZR primers as described above. PCR products were pooled for each independent sample, purified with the QIAquickTM PCR purification kit (Qiagen) as specified by the manufacturer (final volume $30 \mu \mathrm{L}$ ), and cloned with the TOPO TA TM cloning kit (Invitrogen, Carlsbad, California). Plasmids were extracted from isolated clones with the QIAquick ${ }^{\text {TM }}$ plasmid extraction kit (Qiagen). Cloned fragments were re-amplified and the resulting PCR product was subjected to restriction fragment length polymorphism (RFLP) analysis with the restriction endonucleases $S a l$ I and Ncol (Invitrogen). A representative from each restriction class was sequenced and its identity was determined by BLAST search of GenBank.

\section{Excision of nosZ DGGE bands from temperate soils}

The St. Denis National Wildlife Area, $52^{\circ} 12^{\prime} \mathrm{N}, 106^{\circ} 5^{\prime} \mathrm{W}$ (approximately $40 \mathrm{~km}$ east of Saskatoon, Saskatchewan, Canada), is a typical example of the North American prairie pothole region. The research site is a $600 \mathrm{~m} \times 600 \mathrm{~m}$ block of hummocky terrain with many small depressions. Slopes range from $10 \%$ to $15 \%$, and the soils are mapped as unsorted calcarious glacial till and glacio-lacustrine sediments with minor saline glacio-lacustrine (Miller et al. 1985). Soil was collected with a bulk density auger $(15 \mathrm{~cm}$ diameter), and DNA was extracted from the soil with the method described by Griffiths et al. (2000). The nos $Z$ gene was amplified as described above, except the forward primer was replaced by nosZF-GC (GGCGGCGCGCCGCCCGCCCCGCCCCCGTCGCCCCGYTGTTCMTCGACAGCCAG), which contains a GC clamp.

Denaturing gradient gel electrophoresis (DGGE), based on the protocol described by Muyzer et al. (1993), was performed using the Bio-Rad DCode ${ }^{\mathrm{TM}}$ system (Bio-Rad Laboratories, Hercules, California). Aliquots of PCR product were mixed with the required amount of loading buffer $(6 \times)$ and loaded onto $6 \%(\mathrm{~m} / \mathrm{v})$ polyacrylamide gradient gels (37:1 acrylamide-bis-acrylamide, $1.5 \mathrm{~mm}$ thick) in $0.5 \times \mathrm{TAE}$ buffer $(40 \mathrm{mmol} / \mathrm{L}$ Tris, $20 \mathrm{mmol} / \mathrm{L}$ acetic acid, and $1 \mathrm{mmol} / \mathrm{L}$ EDTA) after preconditioning the gel at $60{ }^{\circ} \mathrm{C}$ and $70 \mathrm{~V}$. The linear gradient used was from $40 \%$ to $60 \%$ denaturant, where $100 \%$ denaturing acrylamide was defined as containing $7 \mathrm{~mol} / \mathrm{L}$ urea and $40 \%(\mathrm{v} / \mathrm{v})$ formamide. A $10 \mathrm{~mL}$ stacking gel containing no denaturants was added. Gels were run for $15 \mathrm{~min}$ at $70 \mathrm{~V}$ and then for $16 \mathrm{~h}$ at $40 \mathrm{~V}$ in $0.5 \times \mathrm{TAE}$ buffer at a constant temperature of $60{ }^{\circ} \mathrm{C}$. To visualize bands, gels were stained with SYBR $^{(\mathbf{R}}$ Green I (Sigma-Aldrich Chemie GmbH, Steinheim, Germany) diluted in $2 \mu \mathrm{L}$ in $20 \mu \mathrm{L} 0.5 \times$ TAE) for $12 \mathrm{~min}$ with gentle agitation prior to UV transillumination. Gel images were photographed with a Nikon CoolPix 4500 camera equipped with a SYBR Green filter. Prominent DGGE bands were excised and the entrained DNA was eluted by centrifugation at $14500 \mathrm{~g}$ for $15 \mathrm{~min}$ in $25 \mu \mathrm{L} \mathrm{TE}$ buffer $(10 \mathrm{mmol} / \mathrm{L}$, pH 8.0). Eluted DNA fragments were re-amplified by PCR and purified for sequencing with the QIAquick ${ }^{T M}$ PCR purification kit (Qiagen); the final elution volume was $30 \mu \mathrm{L}$. DNA sequencing was carried out by The National Research Council - Plant Biotechnology Institute DNA Sequencing Lab (Saskatoon, Saskatchewan) using the forward primers nosZF.

Phylogenetic trees were constructed by retrieving similar sequences from GenBank with the BLASTn feature (Altschul et al. 1990), aligning the sequences using the ClustalW function of the BioEdit software, and building the tree with the MAXIMUM LIKELIHOOD option in DNADIST and the NEIGHBOR-JOINING option in the NEIGHBOR functions of PHYLIP (Felsenstein 1989).

\section{Creation of model communities}

Ninety-one model communities were created by pooling 
Fig. 2. Efficiencies of the quantitative polymerase chain reactions for each nos $Z$ sequence. Bars represent the mean efficiency determined by linear regression of five gene concentrations performed in duplicate and error bars are the standard error of the estimate. The dashed line in each panel indicates the average efficiency for that particular group of nos $Z$ genotypes.

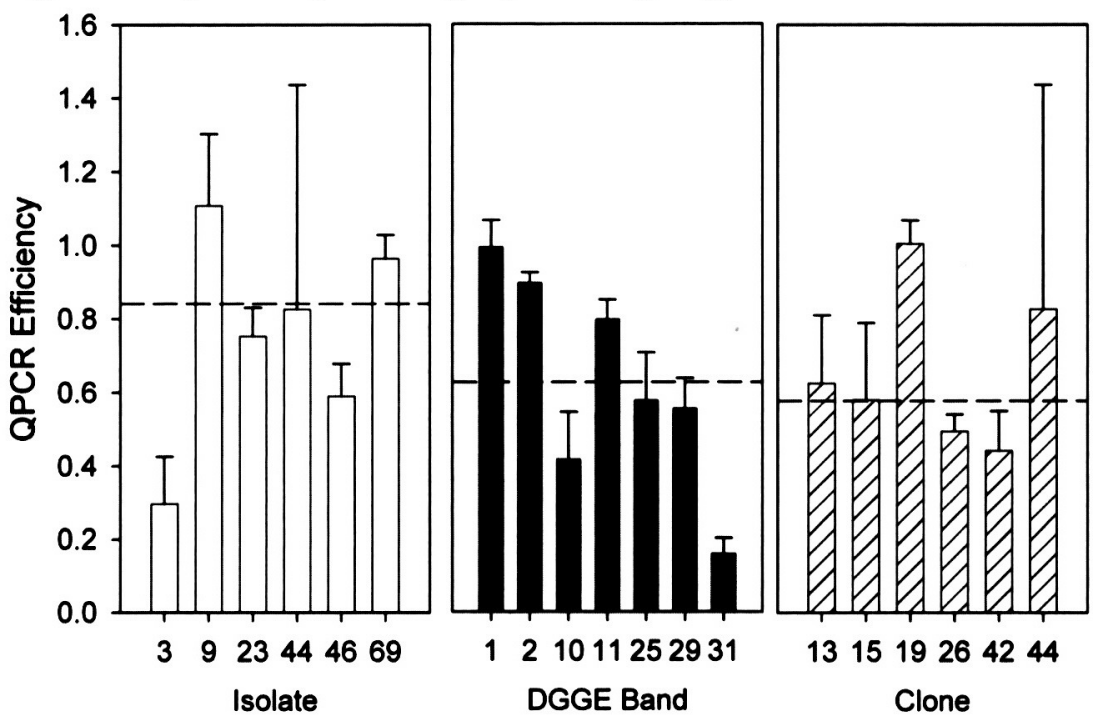

different concentrations ranging from 1 to $3 \mu \mathrm{L}\left(10^{6}-10^{8}\right.$ nos $Z$ copies) of DNA from isolate, DGGE band, or clone nos $Z$ fragments present in each community where possible. Based on nos $Z$ fragment concentrations, 91 model communities were designed. There were 28 different binary, 28 tertiary, 28 ternary, and 7 six-member communities. These communities were created by selecting four different suites of templates (ranging from 2 to 6 unique templates, depending on the community richness) and then seven different combinations of each suite of templates to provide a wide range of total nos $Z$ concentrations. For example, one binary suite of templates was composed of isolate 69 and isolate 9 . Seven different combinations of these two nos $Z$ templates were created to provide a range of nos $Z$ concentrations in which the ratio of isolate 69 to isolate 9 was varied. This was repeated for three more two-template concentrations. Each of these combinations is termed a community. nos $Z$ DNA fragments were first diluted 1:50 and the DNA and nosZ concentration determined spectrophotometrically. QPCR efficiency of each individual template was compared to the Pseudomonas stutzeri ATCC 14405 standard curve and this efficiency was used to calculate the expected nos $Z$ concentrations for the community. The appropriate volume of each nos $Z$ fragment was pipetted into a $20 \mu \mathrm{L}$ volume. subsamples of this mixture were then transferred into a 95 well QPCR microtiter plate, and nosZ gene prevalence was assessed using the QPCR technique described below.

\section{Quantitative PCR of nosZ}

nos $Z$ gene concentrations in DNA were assessed by QPCR with the Quantitect ${ }^{\text {TM }}$ SYBRgreen real-time PCR kit (Qiagen) and an ABI 7500 real-time PCR machine (Applied Biosystems). Each $25 \mu \mathrm{L}$ reaction contained $12.5 \mu \mathrm{L}$ of Mastermix $^{\text {TM }}, 10$ pmol of the nosZF (CGYTGTTCMTCGACAGCCAG) and nosZR (CATGTGCAGNGCRTGGCAGAA) primers (Kloos et al. 2001), and approximately 20-100 ng of template DNA. The template DNA used in the QPCR consisted of purified PCR amplicons for each of the following sources: genomic DNA from the isolates, plasmid DNA from the clones and the DGGE gel-extracted DNA for the DGGE bands. The thermal cycling program was performed as follows: $97{ }^{\circ} \mathrm{C}$ for $15 \mathrm{~min}$; followed by 45 cycles of $94{ }^{\circ} \mathrm{C}$ for $20 \mathrm{~s}, 54{ }^{\circ} \mathrm{C}$ for $40 \mathrm{~s}, 72{ }^{\circ} \mathrm{C}$ for $40 \mathrm{~s}$, and $77{ }^{\circ} \mathrm{C}$ for $45 \mathrm{~s}$; followed by a melt curve from 50 to $95{ }^{\circ} \mathrm{C}$. The data were collected during the $45 \mathrm{~s}$ step at $77^{\circ} \mathrm{C}$.

A standard curve was generated using DNA extracted from $P$. stutzeri ATTC 14405 . The amount of DNA in the extract was determined spectrophotometrically and the number of copies of nos $Z$ genes were calculated assuming that the genome size was $6 \mathrm{Mbp}$ (Fogel et al. 1999) and that there was one copy of nos $Z$ gene per genome. The standard curve was linear over five orders of magnitude with $r^{2}>$ 0.99. The QPCR efficiency for P. stutzeri was $87 \%$. Dissociation curves were performed every run to confirm reaction specificity.

Efficiency of the PCR reactions was assessed by creating a five point curve (in duplicate) of differing gene concentrations. The log of $N_{0}$ (initial gene copy number) was plotted against $C_{\mathrm{t}}$ (cycle number at which the fluorescence differs significantly from background). The slope of $\log \left(N_{0}\right) / C_{t}$ was determined using the LINEST function of Microsoft Excel $^{\mathrm{TM}}$. Efficiency was then derived using the following equation (Rutledge and Cote 2003; Nogva and Rudi 2004):

$$
\text { [2] } E=10^{-1 \cdot \text { Slope }}-1
$$

The standard error of PCR efficiency was derived from the standard error of the slope. PCR efficiencies of the three DNA preparations - isolates, clones, and DGGE bands were compared using a one-way Analysis of Variance (ANOVA) after confirming that the data were normally distributed and had homogenous variances among treatment groups. Multiple comparisons of PCR efficiencies were performed using the Tukey's test at 0.05 . 

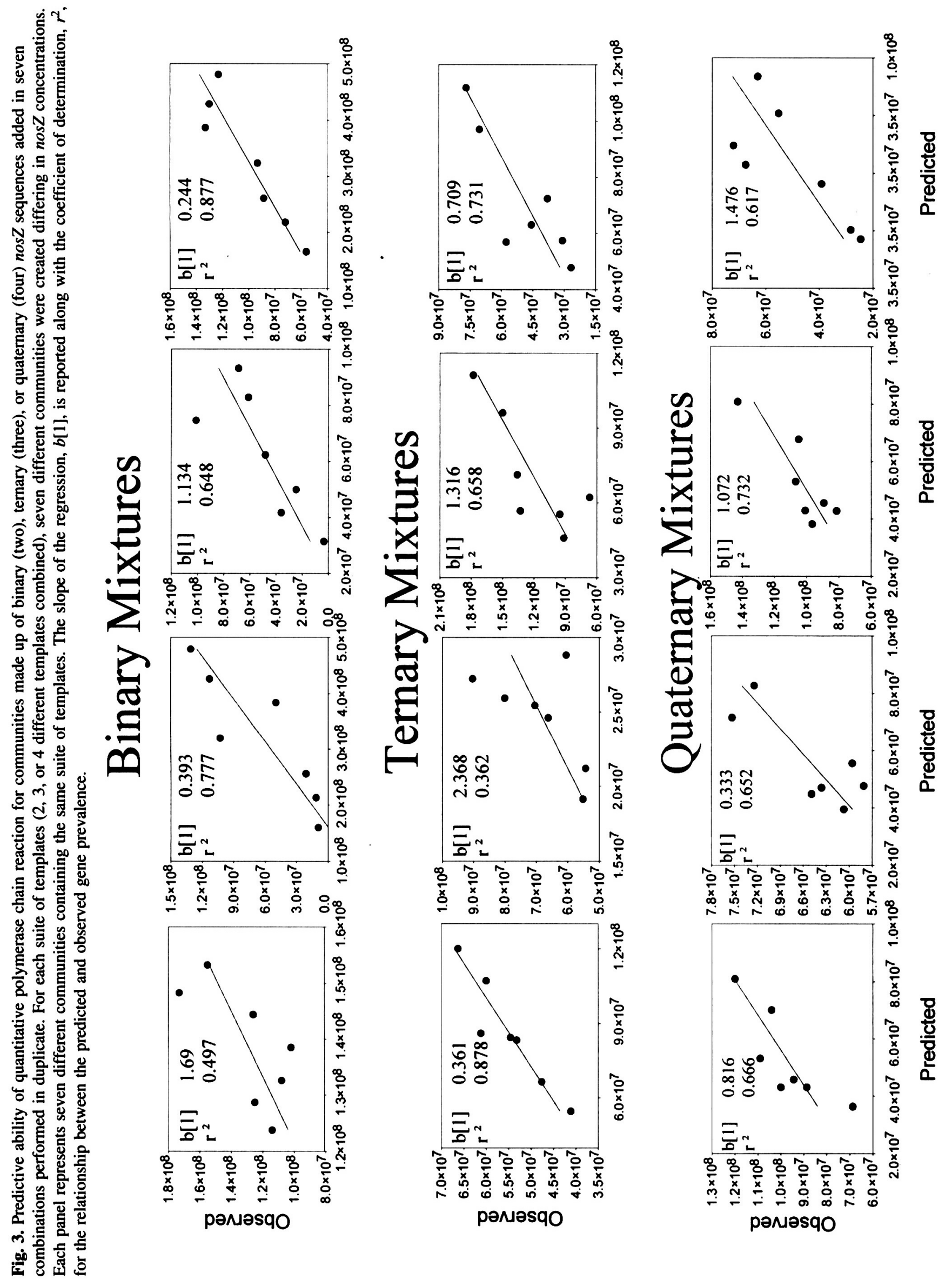


\section{Results and discussion}

A diverse group of nos $Z$ sequences were obtained from the three methods and locations (Fig. 1). The nos $Z$ sequences covered a variety of denitrifiers, ranging from Bradyrhizobium through Pseudomonas to the Alcaligenes genera (Fig. 1). The range of sequences should provide a conservative test of the ability of QPCR to estimate gene prevalence in multi-template reactions.

The QPCR efficiency did not vary significantly between individual templates $(P>0.05$ : Tukey) but was different when templates were grouped according to DNA isolation technique: isolates, DGGE bands, and clone $(P<0.091$ : one-way ANOVA; Fig. 2). The isolates had the greatest QPCR efficiency $(0.848, S D=0.107)$ and were higher than DGGE bands $(0.627, \mathrm{SD}=0.074)$ and clones $(0.578, \mathrm{SD}=$ 0.080 ). There was no significant difference between DGGE bands and clones. Our experimental design did not allow us to directly assess the effects of geographical factors (Arctic, Antarctic, temperate) or technique influences (isolates, DGGE, clones) on the QPCR efficiency. However, nosZ sequences often differ among geographic locations (Rich et al. 2003); therefore, we used the genetic distance from a reference organism (i.e., Ralstonia eutropha $\mathrm{H} 16$; see Fig. 1) as a surrogate for geographical effects on QPCR efficiency. There was no correlation $(r=0.0439)$ between the genetic relationship of a gene target with QPCR efficiency (data not shown). We also performed the same assessment for genetic distance from $P$. stutzeri and found a very weak correlation $(r=-0.49)$. We speculate that different approaches to acquiring template DNA may result in differing QPCR efficiencies.

We evaluated whether QPCR of a nosZ gene would provide an accurate analysis of gene target prevalence if there was more than one template present in the mixture. Ninetyone communities were created and analyzed in duplicate. These communities consisted of two (binary), three (ternary), four (quaternary), or six members. QPCR successfully predicted the nos $Z$ prevalence of these communities (Fig. 3). The accuracy of the QPCR, as measured by the slope of the line between predicted and observed genotype abundance, did not differ between communities of differing nos $Z$ richness. Nor did the accuracy of QPCR depend on the composition of the model communities with different template concentrations resulting in similar predicted-observed relationships. The slopes averaged $0.865(\mathrm{SE}=0.337, n=4)$ for binary, $1.188(\mathrm{SE}=0.44, n=4)$ for ternary, 0.924 $(\mathrm{SE}=0.239, n=4)$ for quaternary, and $1.097\left(r^{2}=0.72\right)$ for the six-member community. The power of the statistical test was only 0.570 , which is below a typical value of 0.8 ; therefore, the lack of statistical difference between slopes may be because of the high variability associated with the slopes. Predictive accuracy also did not depend on nos $Z$ richness. Predictive power, as determined by the coefficient of determination, or $r^{2}$, was similar among the three groups, with $r^{2}$ ranging from $0.7(\mathrm{SE}=0.082, n=4)$ for binary, $0.657(\mathrm{SE}=0.217, n=4)$ for ternary, $0.683(\mathrm{SE}=0.025$, $n=4)$ for quaternary, and $0.72(n=1)$ for six-member communities. Thus, it appears that QPCR is able to successfully predict nos $Z$ gene prevalence in communities consisting of up to six denitrifiers.
Our data indicate that although nos $Z$ QPCR efficiencies differ, there are no statistically significant differences between nosZ QPCR efficiencies for different templates. QPCR efficiency variability can result in at least two distinct artifacts during an ecological study. A low efficiency genotype present in the environment may be compared to a high efficiency standard curve, and consequently, genotype abundance in the environment may be grossly underestimated. In addition, changes in the prevalence of a low efficiency genotype in a community of higher efficiency genotypes may not be detected. For example, in QPCR systems targeting catabolic genes (Beller et al. 2002) in which the slope of $\log \left(N_{0}\right) / C_{\mathrm{t}}$ differ by $3.7 \%$ or an efficiency difference of 0.11 , the low efficiency targets would need to increase by sixfold before the QPCR technique could detect a difference between the baseline community and the community enriched with low efficiency targets. Investigators should be aware that these artifacts are highly dependent on the $C_{\mathrm{t}}$ used in their system because increasing $C_{\mathrm{t}}$ exacerbates small differences in PCR efficiency because of the exponential effect of $C_{\mathrm{t}}$ on $N_{0}$.

Our results confirm that QPCR efficiencies can vary among templates. However, this variation is not statistically significant. This variation is not linked to genetic distance from a reference organism and is likely because of random variation from procedural effects and fundamental variance between templates that influences amplication efficiency such as tertiary DNA structure. The effects of this variability in QPCR efficiency between genotypes is exacerbated at large $C_{\mathrm{t}}$ values. Thus, investigators should use the highest practical DNA concentration and select the lowest possible $C_{\mathrm{t}}$ value. In a soil microbial ecology setting where one expects to be analyzing communities with thousands of different templates, the statistically insignificant biases we have observed in this study will likely not alter the overall conclusions of field studies because individual templates with differing efficiencies will not significantly alter the results in a community in which there are 1000 templates. However, it is possible that these biases and differences in QPCR efficiencies could be of concern for other target genes and community types, especially in communities in which there are only a very few number of different templates. Investigators should confirm that QPCR efficiencies of their target genes in environmental samples are similar to their reference gene used to construct standard curves.

\section{Acknowledgements}

We would like to acknowledge that the comments of a reviewer on a previous paper provided the stimulus for us to begin this study. Our research was made possible by the logistical support of the Polar Continental Shelf Project (Project No. 608-04) and a National Engineering and Research Council of Canada Discovery Grant to S.D.S.

\section{References}

Altschul, S.F., Gish, W., Miller, W., Myers, E.W., and Lipman, D.J. 1990. Basic local alignment search tool. J. Mol. Biol. 215: 403-410. doi:10.1006/jmbi.1990.9999. PMID:2231712.

Anderson, I.C., Campbell, C.D., and Prosser, J.I. 2003. Potential bias of fungal $18 \mathrm{~S}$ rDNA and internal transcribed spacer polymerase chain reaction primers for estimating fungal biodiversity 
in soil. Environ. Microbiol. 5: 36-47. doi:10.1046/j.1462-2920. 2003.00383.x. PMID:12542711.

Baldwin, B.R., Nakatsu, C.H., and Nies, L. 2003. Detection and enumeration of aromatic oxygenase genes by multiplex and real-time PCR. Appl. Environ. Microbiol. 69: 3350-3358. doi:10.1128/AEM.69.6.3350-3358.2003. PMID:12788736.

Beller, H.R., Kane, S.R., Legler, T.C., and Alvarez, P.J. 2002. A real-time polymerase chain reaction method for monitoring anaerobic, hydrocarbon-degrading bacteria based on a catabolic gene. Environ. Sci. Technol. 36: 3977-3984. doi:10.1021/ es025556w. PMID:12269751.

Berthelet, M., Whyte, L.G., and Greer, C.W. 1996. Rapid, direct extraction of DNA from soils for PCR analysis using polyvinylpolypyrrolidone spin columns. FEMS Microbiol. Lett. 138: 1722. doi:10.1111/j.1574-6968.1996.tb08128.x. PMID:8674967.

Felsenstein, J. 1989. PHYLIP (phylogenetic inference program package) version 3.2. Cladistics, 5: 164-166.

Fierer, N., Jackson, J.A., Vilgalys, R., and Jackson, R.B. 2005. Assessment of soil microbial community structure by use of taxonspecific quantitative PCR assays. Appl. Environ. Microbiol. 71: 4117-4120. doi:10.1128/AEM.71.7.4117-4120.2005. PMID: 16000830 .

Fogel, G.B., Li, C.C., and Brunk, J. 1999. Prokaryotic genome size and SSU rDNA copy number: estimation of microbial relative abundance from a mixed population. Microb. Ecol. 38: 93-113. doi:10.1007/s002489900162. PMID: 10441703.

Freeman, W.M., Walker, S.J., and Vrana, K.E. 1999. Quantitative RT-PCR: pitfalls and potential. Biotechniques, 26: 112-125. PMID:9894600.

Giglio, S., Monis, P.T., and Saint, C.P. 2003. Demonstration of preferential binding of SYBR Green I to specific DNA fragments in real-time multi-plex PCR. Nucleic Acids Res. 31: e136. doi:10.1093/nar/gng 135. PMID: 14602929.

Griffiths, R.I., Whiteley, A.S., O'Donnell, A.G., and Bailey, M.J. 2000. Rapid method for coextraction of DNA and RNA from natural environments for analysis of ribosomal-DNA and rRNAbased microbial community composition. Appl. Environ. Microbiol. 66: 5488-5491. doi:10.1128/AEM.66.12.5488-5491.2000. PMID:1 1097934.

Hall, S.J., Hugenholtz, P., Siyambalapitiya, N., Keller, J., and Blackall, L.L. 2002. The development and use of real-time PCR for the quantification of nitrifiers in activated sludge. Water Sci. Technol. 46: 267-272. PMID:12216635.

Kloos, K., Mergel, A., Rosch, C., and Bothe, H. 2001. Denitrification within the genus Azospirillum and other associative bacteria. Aust. J. Plant Physiol. 28: 991-998.

Lev, A., and King, R.H. 1999. Spatial variation and soil development in high arctic soil landscape: Truelove Lowland, Devon Island, Nunavut, Canada. Permafrost Periglacial Process. 10: 289307.
Miller, J.J., Acton, D.F., and St. Arnaud, R.J. 1985. The effect of groundwater on soil formation in a morainal landscape in Saskatchewan. Can. J. Soil Sci. 65: 293-307.

Muyzer, G., de-Waal, E.C., and Uitterlinden, A.G. 1993. Profiling of complex microbial populations by denaturing gradient gel electrophoresis analysis of polymerase chain reaction-amplified genes coding for 16S rRNA. Appl. Environ. Microbiol. 59: 695-700. PMID:7683183.

Nogva, H.K., and Rudi, K. 2004. Potential influence of the first PCR cycles in real-time comparative gene quantifications. Biotechniques, 37: 246-253. PMID:15335216.

Ott, S.J., Musfeldt, M., Ullmann, U., Hampe, J., and Schreiber, S. 2004. Quantification of intestinal bacterial populations by realtime PCR with a universal primer set and minor groove binder probes: a global approach to the enteric flora. J. Clin. Microbiol. 42: 2566-2572. doi:10.1128/JCM.42.6.2566-2572.2004. PMID: 15184435 .

Polz, M.F., and Cavanaugh, C.M. 1998. Bias in template-to-product ratios in multitemplate PCR. Appl. Environ. Microbiol. 64: 3724-3730. PMID:9758791.

Powell, S.M., Ferguson, S.H., Snape, I., and Siciliano, S.D. 2006. Fertilization stimulates anaerobic fuel degradation of Antarctic soils by denitrifying microorganisms. Environ. Sci. Technol. 40: 2011-2017. doi:10.1021/es051818t. PMID:16570629.

Rich, J.J., Heichen, R.S., Bottomley, P.J., Cromack, K., and Myrold, D.D. 2003. Community composition and functioning of denitrifying bacteria from adjacent meadow and forest soils. Appl. Environ. Microbiol. 69: 5974-5982. doi:10.1128/AEM.69.10. 5974-5982.2003. PMID:14532052.

Rutledge, R.G., and Cote, C. 2003. Mathematics of quantitative kinetic PCR and the application of standard curves. Nucleic Acids Res. 31: e93. doi:10.1093/nar/gng093. PMID: 12907745.

Siciliano, S.D., Roy, R., and Greer, C.W. 2000. Reduction in denitrification activity in field soils exposed to long term contamination by 2,4,6-trinitrotoluene (TNT). FEMS Microbiol. Ecol. 32: 61-68. PMID: 10779620.

Smith, M.S., Yang, R.K., Knapp, C.W., Niu, Y.F., Peak, N., Hanfelt, M.M., Galland, J.C., and Graham, D.W. 2004. Quantification of tetracycline resistance genes in feedlot lagoons by realtime PCR. Appl. Environ. Microbiol. 70: 7372-7377. doi:10. 1128/AEM.70.12.7372-7377.2004. PMID: 15574938.

Sun, Y., Polishchuk, E.A., Radoja, U., and Cullen, W.R. 2004. Identification and quantification of ars $C$ genes in environmental samples by using real-time PCR. J. Microbiol. Methods, 58: 335-349. doi:10.1016/j.mimet.2004.04.015. PMID:15279938.

Suzuki, M.T., and Giovannoni, S.J. 1996. Bias caused by template annealing in the amplification of mixtures of 16S rRNA genes by PCR. Appl. Environ. Microbiol. 62: 625-630. PMID: 8593063. 